Check for updates

Cite this: RSC Adv., 2019, 9, 1562

Received 18th November 2018

Accepted 4th January 2019

DOI: $10.1039 / \mathrm{c} 8 \mathrm{ra09484e}$

rsc.li/rsc-advances

\section{Morphology-controlled synthesis of $\mathrm{CoMoO}_{4}$ nanoarchitectures anchored on carbon cloth for high-efficiency oxygen oxidation reaction $\uparrow$}

\author{
Feifei Wang, $\ddagger^{\mathrm{a}}$ Juan Zhao, $\ddagger^{\mathrm{a}}$ Wen Tian, ${ }^{\mathrm{a}}$ Zhufeng Hu, ${ }^{\mathrm{a}}$ Xingbin Lv, ${ }^{\mathrm{a}}$ Hualian Zhang, ${ }^{{ }^{a}}$ \\ Hairong Yue, (D) ${ }^{a}$ Yuxin Zhang, (D) ${ }^{c}$ Junyi Ji (D) ${ }^{* a b}$ and Wei Jiang (D) ${ }^{a}$
}

Novel $\mathrm{COMoO}_{4}$ nanoarrays with different morphologies are anchored on a carbon cloth via a simple hydrothermal method by adjusting the $\mathrm{Co} / \mathrm{Mo}$ atom ratio. The in situ growth and tight immobilization of the $\mathrm{CoMoO}_{4}$ nanocomposite on the carbon cloth can facilitate the electrolyte infiltration and electrons transfer rate at the contact interface. Therefore, the free-standing electrode of $\mathrm{CoMoO}_{4} /$ carbon cloth with interconnected nanosheets shows superior electrocatalytic activity, and the overpotential of $286 \mathrm{mV}$ is obtained at $15 \mathrm{~mA} \mathrm{~cm}{ }^{-2}$ in alkaline solution. Moreover, the catalyst also exhibits a small Tafel slope of $67 \mathrm{mV} \mathrm{dec}^{-1}$ as well as good stability. The relationship between the active material morphology, contact interface and the electrocatalytic performance is also discussed. As the carbon cloth is commercially available, this simple but effective structural controlling method demonstrates a new large-scale practical electrode fabrication technique for high performance OER electrodes and largescale water splitting.

\section{Introduction}

The ever-growing energy demands and environmental issues have triggered a great research interest in the field of clean and sustainable energy sources. ${ }^{1-4}$ As one of the most popular candidates, hydrogen has aroused great attention owing to its high energy conversion efficiency and carbon-/pollution-free nature. Among the large-scale hydrogen production technologies, the electrocatalytic water splitting method shows great advantages due to its high efficiency, easy-scalability and environmental benignity. ${ }^{5-8}$ However, the anodic oxygen evolution reaction (OER) with multi-electron transfer process, which further hinders the fast reaction kinetics, has been regarded as the bottleneck process of the water splitting. ${ }^{9-11} \mathrm{RuO}_{2}$ and $\mathrm{IrO}_{2}$ are regarded as the excellent OER catalyst, however, their high cost and low abundance have significantly hindered their practical application. ${ }^{12,13}$ Therefore, design and fabrication of the non-noble-metal alternative electrodes with high

${ }^{a}$ School of Chemical Engineering, Sichuan University, Chengdu 610065, P. R. China. E-mail: junyiji@scu.edu.cn

${ }^{b}$ State Key Laboratory of Polymer Materials Engineering, Sichuan University, Chengdu 610065, P. R. China

${ }^{c}$ College of Material Science and Engineering, Chongqing University, Chongqing, 400044, P. R. China

$\dagger$ Electronic supplementary information (ESI) available: SEM images, XRD patterns, XPS spectrums and TEM images of the $\mathrm{CoMoO}_{4} / \mathrm{CC}$ composites before and after long term catalytic stability test, and the $\mathrm{CV}$ curves of composites collected under different scan rates are listed. See DOI: 10.1039/c8ra09484e

\$ The authors contribute equal to this manuscript. electrocatalytic activity and large-scalable fabrication capability is highly demanded.

Transition metal oxides, as one of the efficient OER catalysts in alkaline solution, have aroused great interests owing to the comparable catalytic activity and environmental friendliness compared with the metal phosphide and sulphides. ${ }^{14,15} \mathrm{Among}$ them, Co-based metal oxides composites $\left(\mathrm{Co}_{3} \mathrm{O}_{4}, \mathrm{MnCo}_{2} \mathrm{O}_{4}\right.$, $\mathrm{CoMoO}_{4}$, etc.) have been extensively studied due to the natural abundance and good electrocatalytic properties. ${ }^{16-22}$ Furthermore, the bimetallic $\mathrm{CoMoO}_{4}$ composite can exhibit much better electrochemical property in comparison with the monometallic $\mathrm{Co}_{3} \mathrm{O}_{4}$ or $\mathrm{MoO}_{3}$ due to the synergistic interactions between different elements. ${ }^{23}$ Moreover, the electrocatalytic activity highly depends on the exposed active sites and electrons transfer efficiency to the active materials, and the active sites is further related to the composition, loading mass, crystallinity and defects, etc. Therefore, the morphology design and contact interface control of the active materials are essential for high performance electrocatalysis electrodes. ${ }^{24-26}$ Fabrication of the free-standing composite with active materials coated on the conductive networks is an effective strategy to enhance the electrochemical performance of the electrodes. ${ }^{27,28}$ With the well-designed structure, the electrodes can expose more active sites to the electrolyte, while the engineered contact interface can effectively transfer the electrons from the conductive networks to the active materials. ${ }^{29-31}$ Therefore, large-scale fabrication of the hybrid electrodes with high electrocatalytic performance and simple fabrication process is urgently required for the practical application. 
Herein, the three-dimensional (3D) free-standing $\mathrm{CoMoO}_{4}$ nanoarchitecture anchored on the carbon cloth (CC) is fabricated via a simple one-pot hydrothermal reaction. The $\mathrm{CoMoO}_{4}$ morphology evolution with the change of the Co/Mo precursor ratio is investigated, the relationship between the materials contact interface and the electrocatalytic performance is also discussed. As an OER electrode, the as-prepared $\mathrm{CoMoO}_{4} / \mathrm{CC}-2$ composite with interconnected nanosheets reveals superior catalytic activity, an overpotential of $286 \mathrm{mV}$ can be obtained at a geometrical catalytic current density of $15 \mathrm{~mA} \mathrm{~cm}{ }^{-2}$ in $1.0 \mathrm{M}$ $\mathrm{KOH}$. Moreover, the $\mathrm{CoMoO}_{4} / \mathrm{CC}-2$ electrode shows high longterm OER performance with the activity unchanged for $20 \mathrm{~h}$. As the carbon cloth is commercially available, this simple but effective hydrothermal method demonstrates a new large-scale practical electrode fabrication technique for high performance OER electrodes.

\section{Experimental section}

\subsection{Synthesis of the $\mathrm{CoMoO}_{4} / \mathrm{CC}$ composite}

All the materials were purchased from Aladdin Co. The carbon cloth $(2 \mathrm{~cm} \times 2 \mathrm{~cm}$, WOS 1009, CeTech Co. Ltd, China) was first washed with ethanol under sonication to remove the impurities, and then pretreated with $0.5 \mathrm{M} \mathrm{KMnO}_{4}$ for $0.5 \mathrm{~h}$ to provide seed crystal. ${ }^{32}$ The self-supported $\mathrm{CoMoO}_{4}$ arrays with different morphologies anchored on carbon cloth were synthesized by one-step hydrothermal reaction. In a typical process, $n \mathrm{mmol}$ $\mathrm{Co}\left(\mathrm{NO}_{3}\right)_{2} \cdot 6 \mathrm{H}_{2} \mathrm{O}(n=0.3125,0.625,1.25,2.5)$ and $2.5 \mathrm{mmol}$ $\mathrm{Na}_{2} \mathrm{MoO}_{4} \cdot 2 \mathrm{H}_{2} \mathrm{O}$ were added into $50 \mathrm{~mL}$ deionized water and mixed for 15 min to form a homogeneous pink solution. Then, the pretreated carbon cloth and the solution were transferred into a $50 \mathrm{~mL}$ autoclave and kept at $140{ }^{\circ} \mathrm{C}$ for $4 \mathrm{~h}$. After cooling to room temperature naturally, the obtained samples were washed with DI water and ethanol, then dried at $50{ }^{\circ} \mathrm{C}$ for $6 \mathrm{~h}$, and the $\mathrm{CoMoO}_{4}$ nanostructure anchored on carbon cloth was finally obtained. And the loading mass of the active materials is listed in Table S1 (see ESI $\dagger$ ). The commercial $\mathrm{IrO}_{2}$ electrode was purchased from the Kunshan Yiwanlin Electronic Technology Co., Ltd.

\subsection{Material characterization}

The microscopic structure and morphology were characterized by scanning electron microscopy (JEOL JSM-7610F Field Emission) and transmission electron microscopy (FEI Tecnai G20). The X-ray diffraction were carried out to ensure the crystal structure ( $\mathrm{Cu} \mathrm{K} \alpha$ radiation). The X-ray photoelectron spectroscope was conducted on a PHI5000 Versa spectrometer. Raman spectrum were measured by DXRxi spectrometer (Thermo) with $455 \mathrm{~nm}$ laser.

\subsection{Electrochemical measurements}

Three-electrode system was fabricated to tested the electrochemical performance by the electrochemical workstation (CHI 760E). In this system, the free-standing $\mathrm{CoMoO}_{4} / \mathrm{CC}$ composite was used as the working electrode directly, and the carbon rod and $\mathrm{Ag} / \mathrm{AgCl}$ ( $\mathrm{KCl}$, saturated) were employed as counter electrode and reference electrode, respectively. All the operation potentials were calibrated to RHE according to the equation: $E_{\mathrm{RHE}}=E_{\mathrm{Ag} / \mathrm{AgCl}}+0.197+0.059 \times \mathrm{pH}$. The linear sweep voltammetry (LSV) was conducted from 0 to $0.6 \mathrm{~V}$ ( $v s . \mathrm{Ag} / \mathrm{AgCl})$ at $5 \mathrm{mV} \mathrm{s}^{-1}$ in $1 \mathrm{M} \mathrm{KOH}(\mathrm{pH}=14)$. The LSV curves and corresponding Tafel slopes were obtained with $i R$ compensation. And the cyclic voltammetry and chronopotentiometric tests were conducted without $i R$ compensation. Electrochemical impedance spectroscopy (EIS) measurement was conducted in a frequency ranging from $100 \mathrm{kHz}$ to $0.01 \mathrm{~Hz}$ at $5 \mathrm{mV} \mathrm{s}^{-1}$. The current density of the multi-current test starts at $10 \mathrm{~mA} \mathrm{~cm} \mathrm{~cm}^{-2}$ and ends at $50 \mathrm{~mA} \mathrm{~cm}{ }^{-2}\left(5 \mathrm{~mA} \mathrm{~cm}^{-2}\right.$ per $500 \mathrm{~s}$ without $i R$ correction). To measure the electrochemical surface area (ECSA) of all the samples, the $C_{\mathrm{dl}}$ was calculated according to the cyclic voltammograms curves with different scan rate. The long-term stability of the composite was conducted by the $i-t$ curve at a constant working potential of $1.6 \mathrm{~V}$ for $20 \mathrm{~h}$.

\section{Results and discussion}

The crystalline structure of the $\mathrm{CoMoO}_{4} / \mathrm{CC}-n(n=1,2,3$ and 4$)$ composites is tested by XRD (Fig. 1a). Besides the apparent diffraction peaks of the CC scaffold, the small shoulder peaks located at $23.3^{\circ}, 25.5^{\circ}, 26.5^{\circ}, 28.4^{\circ}$ and $33.7^{\circ}$ can be indexed to the (021), (201), (002), (-311) and (-222) planes of the $\mathrm{CoMoO}_{4}$ (JCPDS no. 21-0868), respectively. Moreover, the $\mathrm{CoMoO}_{4} / \mathrm{CC}-4$ composite shows no obvious characteristic peaks of the $\mathrm{CoMoO}_{4}$, which may be due to the low crystalline degree of the $\mathrm{CoMoO}_{4}$ structure. Moreover, the XRD pattern of the powder collected from the solution also certifies the existence of the $\mathrm{CoMoO}_{4}$ crystalline (Fig. S1, see ESI $\dagger$ ). The Raman spectroscopy was further applied to illustrate the crystalline and bonding nature of the as-prepared composites (Fig. 1b). The two characteristic peaks located at $1363 \mathrm{~cm}^{-1}$ (D band) and $1588 \mathrm{~cm}^{-1}$ ( $\mathrm{G}$ band) can be assigned to the carbon cloth. The $\mathrm{CoMoO}_{4} / \mathrm{CC}-2$ composite exhibits good $\mathrm{CoMoO}_{4}$ crystallinity in comparison with that of the $\mathrm{CoMoO}_{4} / \mathrm{CC}-n(n=1,3,4)$, the three major bands can be observed at 326, 802 and $904 \mathrm{~cm}^{-1}$. The band centred at $326 \mathrm{~cm}^{-1}$ is attributed to the symmetric stretching of the Co-O-Mo bond. The band located at $802 \mathrm{~cm}^{-1}$ is associated with asymmetric stretching modes of $\mathrm{O}-\mathrm{Mo}-\mathrm{O}$ bond while the band at $904 \mathrm{~cm}^{-1}$ corresponds to the symmetric stretching mode of Mo-O bond. ${ }^{33,34}$ The slight variations in the positions of the vibrational modes may be due to the crystal size, morphology and strength of interaction between the ions and the structural order-disorder degree of the composites. ${ }^{35}$

The XPS is also conducted to confirm the oxidation valence states of the $\mathrm{CoMoO}_{4} / \mathrm{CC}-2$ composite. The full survey spectrum in Fig. 2a indicates the presence of the Mo, Co and $\mathrm{O}$ elements in the composite and the unequal atomic ratio of $\mathrm{Co} / \mathrm{Mo}$ elements are listed in Table $\mathrm{S} 2, \uparrow$ illustrating partial doping of Co element into the $\mathrm{CoMoO}_{4}$ composite. The deconvolution of the Co 2p spectrum in Fig. 2a shows two peaks, the peaks centred at $781.0 \mathrm{eV}$ and $796.0 \mathrm{eV}$ are related to the Co $2 \mathrm{p}_{3 / 2}$ and Co $2 \mathrm{p}_{1 / 2}$, respectively, which refer to $\mathrm{Co}^{2+}$ species. ${ }^{36}$ Moreover, the apparent satellite peaks of the Co $2 p$ spectrum also verify the existence of the Co(II). For the Mo 3d spectrum (Fig. 2c), the 

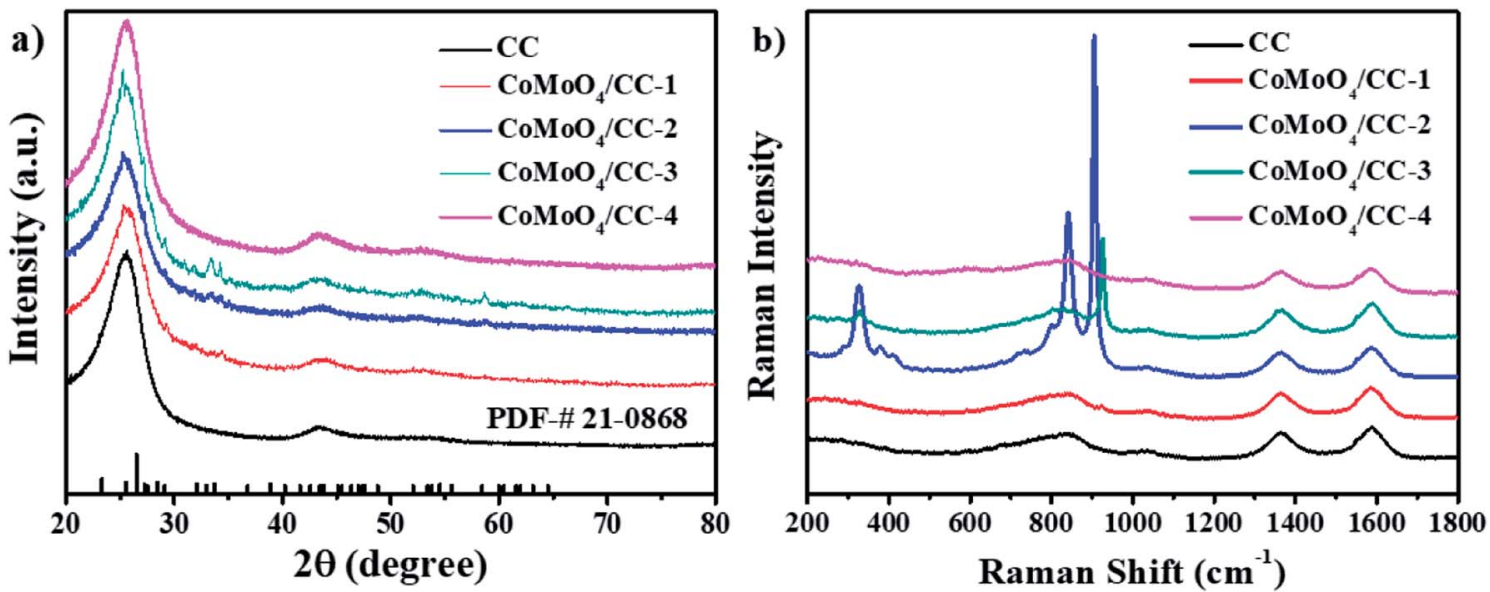

Fig. 1 (a) XRD patterns (b) Raman spectra of the as-prepared $\mathrm{CoMoO}_{4} / \mathrm{CC}-n(n=1,2,3$ and 4$)$ and raw carbon cloth.

binding energy located at $232.9 \mathrm{eV}$ and $235.3 \mathrm{eV}$ can be specified as Mo d $_{5 / 2}$ and Mo d $_{3 / 2}$ of the $\mathrm{Mo}^{6+}$ species, respectively, which is in line with the valance state of the $\mathrm{MoO}_{4}{ }^{2-}$ precursor. ${ }^{18,37}$ In the $\mathrm{O} 1 \mathrm{~s}$ region (Fig. 2d), two peaks around $530.5 \mathrm{eV}$ and $532.1 \mathrm{eV}$ are corresponding to the $\mathrm{Mo}-\mathrm{O}$ and $\mathrm{Co}-\mathrm{O}$, respectively. ${ }^{38,39}$ Therefore, the XPS results demonstrate the successful fabrication of the $\mathrm{CoMoO}_{4}$ materials on the carbon cloth.
The morphology evolution and the microstructure of the $\mathrm{CoMoO}_{4} / \mathrm{CC}$ hybrids are investigated by SEM analysis. As shown in the low-magnification images (Fig. S2 $\dagger$ ), the hierarchical $\mathrm{CoMoO}_{4}$ architectures with different morphologies are uniformly and seamlessly anchored on the surface of the carbon cloth, further demonstrating the simple but effective large-scale active material coating strategy. The EDS images of
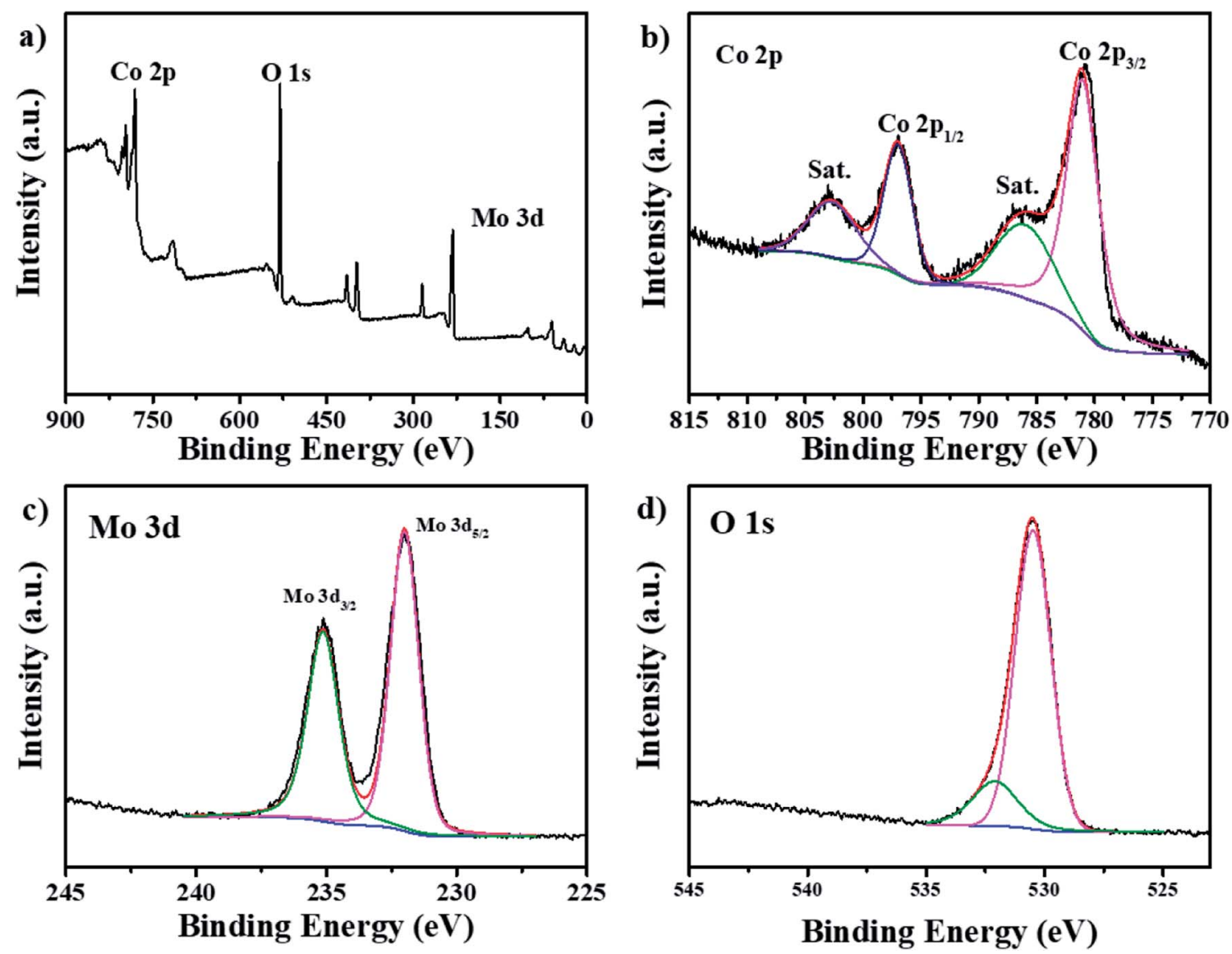

Fig. 2 XPS spectra of (a) full survey, (b) $\mathrm{Co} 2 \mathrm{p}$, (c) Mo 3d and (d) O 1 s of the $\mathrm{CoMoO}_{4} / \mathrm{CC}$-2 electrode. 
the $\mathrm{CoMoO}_{4} / \mathrm{CC}-2$ (Fig. 3e) illustrate all the elements (Co, Mo and $\mathrm{O}$ ) are uniformly dispersed on the CC surface, indicating the uniform distribution of the $\mathrm{CoMoO}_{4}$ nanosheets. Under higher magnification (Fig. 3), the $\mathrm{CoMoO}_{4}$ architectures exhibit distinct morphology evolution with the increment of the Co/Mo ratio during hydrothermal process. The $\mathrm{CoMoO}_{4}$ architecture is constructed by the interconnected nanosheets with high porosity under lower $\mathrm{Co} / \mathrm{Mo}$ ratio $(1: 8$, and $1: 4)$ (Fig. 3a and b), while the structure of the nanosheets turns from wrinkled and irregular structure of $\mathrm{CoMoO}_{4} / \mathrm{CC}-1$ to more ideal nanosheets crystals of $\mathrm{CoMoO}_{4} / \mathrm{CC}-2$. Moreover, with higher Co ions concentration, the thickness of the nanosheets increases from less than $10 \mathrm{~nm}$ to around $16 \mathrm{~nm}$. Furthermore, the $\mathrm{CoMoO}_{4} / \mathrm{CC}-3$ (Fig. 3c) displays the hybrid $\mathrm{CoMoO}_{4}$ nanostructure with both nanosheets and nanorods coexisted, while the nanosheets reveal increased plate size and thickness. When the Co/Mo ratio increased to a higher level of $1: 1$ (Fig. 3d), the nanostructure of the $\mathrm{CoMoO}_{4}$ changed to nanorods arrays vertically aligned on the surface of the carbon cloth. The morphology evolution with the change of the $\mathrm{Co} / \mathrm{Mo}$ ratio may be due to the shape-controlled effects of $\mathrm{Co}^{2+}$ during hydrothermal reaction: with the increment of the $\mathrm{Co}^{2+}$ concentration, the nuclei density of the $\mathrm{CoMoO}_{4}$ increases at the carbon cloth interface as well as in the solution, which further influences the growth rate and the crystalline structure of the nanostructures. Moreover, the contact interface of these electrodes may differ with the different $\mathrm{CoMoO}_{4}$ morphology and thickness, the larger contact interface may be beneficial to the electrons transfer rate from the carbon cloth to $\mathrm{CoMoO}_{4}$, thus influencing the active sites utilization efficiency. ${ }^{40}$

The surface morphology and crystalline feature of the $\mathrm{CoMoO}_{4} / \mathrm{CC}-2$ composite is further confirmed by TEM test. As shown in Fig. 4a, the $\mathrm{CoMoO}_{4}$ nanosheets exhibit layered and quasi-hexagonal structure, indicating the relatively good crystalline structure of the nanosheets. The high resolution image in Fig. $4 \mathrm{~b}$ illustrates the formation of mesoporous structures on the $\mathrm{CoMoO}_{4}$ nanosheets, which may result from the crystal defects of the nanosheets. These defective hexagonal structure
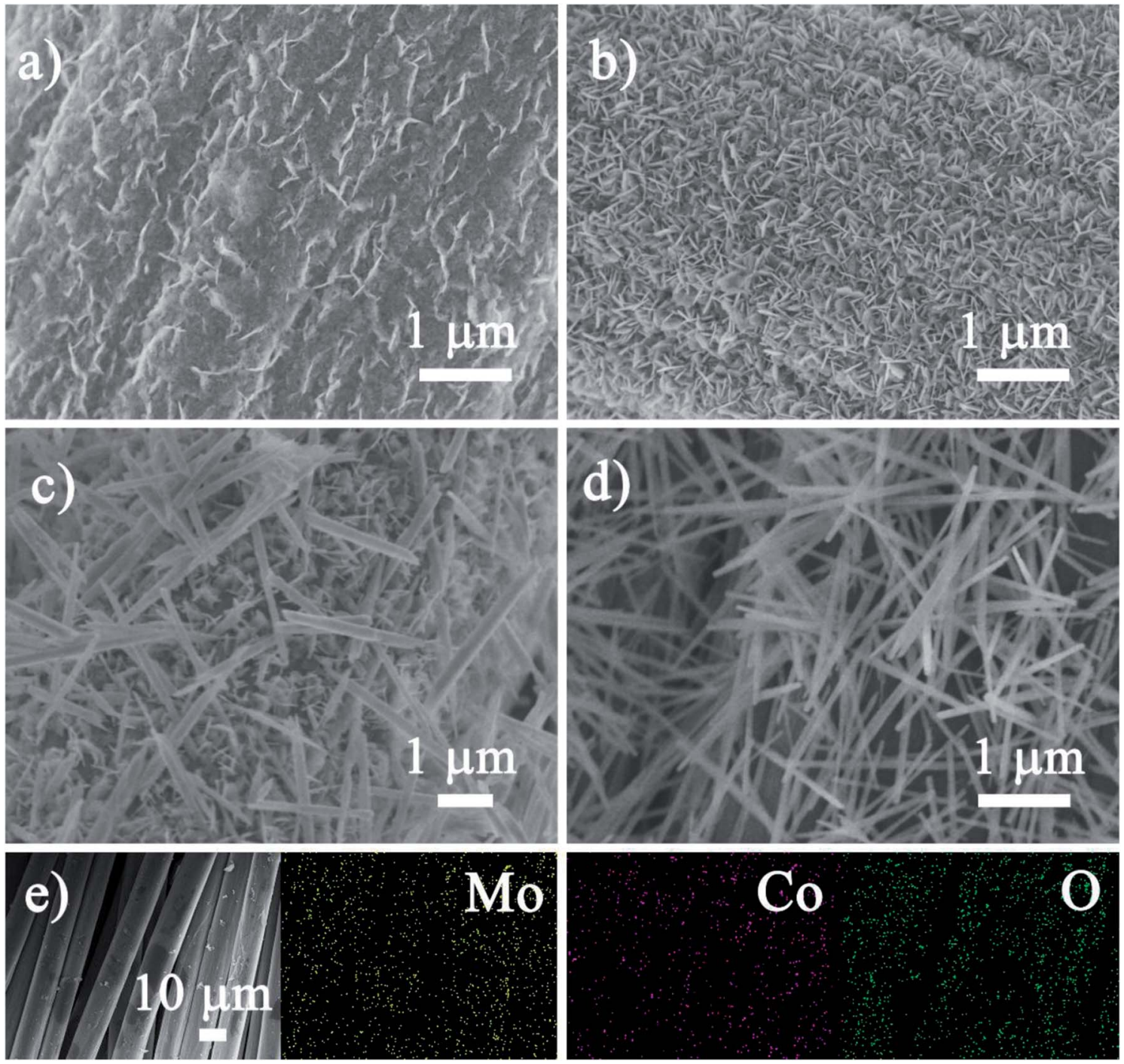

Fig. $3 \mathrm{SEM}$ images of the (a) $\mathrm{COMoO}_{4} / \mathrm{CC}-1$, (b) $\mathrm{COMoO}_{4} / \mathrm{CC}-2$ and (c) $\mathrm{CoMoO}_{4} / \mathrm{CC}-3$ and (d) $\mathrm{CoMoO}$ / $/ \mathrm{CC}-4$, (e) the SEM image and corresponding elemental mapping of $\mathrm{Mo}, \mathrm{Co}$ and $\mathrm{O}$ of the $\mathrm{CoMoO}_{4} / \mathrm{CC}-2$. 

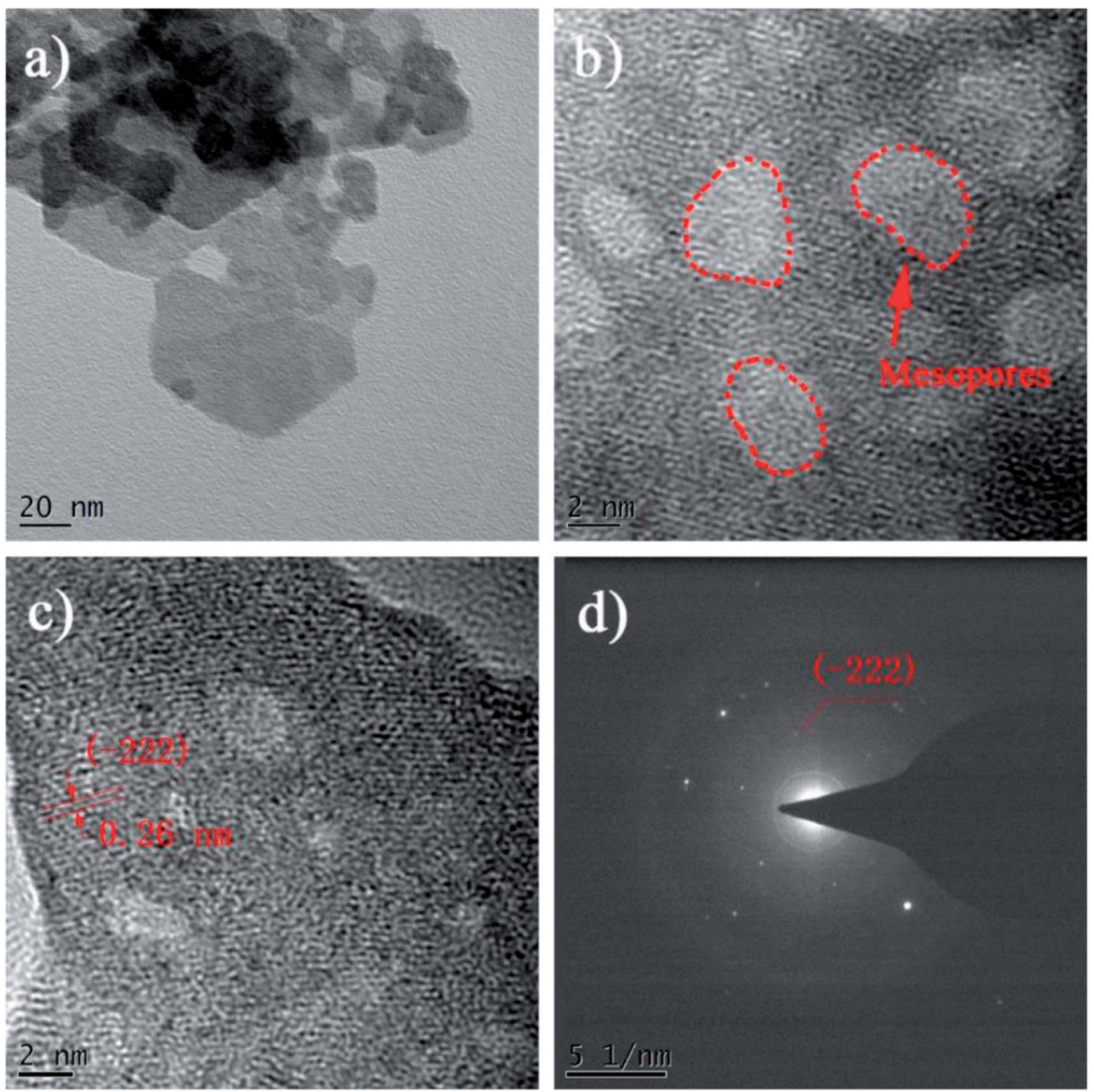

Fig. 4 TEM images of the $\mathrm{CoMoO}_{4} / \mathrm{CC}-2$ composite, (a) the $\mathrm{CoMoO}_{4}$ nanosheets, (b and $\mathrm{c}$ ) the high-resolution image of the CoMoO 4 nanosheets and (d) the SAED pattern acquired from $\mathrm{CoMoO}_{4}$ nanosheets.

and porous defects can provide sufficient active sites for the electrocatalytic reaction. ${ }^{\mathbf{4 1 , 4 2}}$ Moreover, Fig. 4c reveals the defective polycrystalline structure of the as-prepared $\mathrm{CoMoO}_{4}$ nanosheets, and the lattice fringe of $0.26 \mathrm{~nm}$ can be related to the $(-222)$ plane of $\mathrm{CoMoO}_{4}$. Moreover, the crystalline structure is further confirmed by the selected area electron diffraction (SAED) pattern (Fig. 4d), the (-222) plane is in line with the XRD results. Similar crystalline structure can also be observed from the TEM images of the $\mathrm{CoMoO}_{4} / \mathrm{CC}-3$ composite (Fig. S3, see ESI $\dagger$ ). Therefore, the $\mathrm{CoMoO}_{4} / \mathrm{CC}$ composites may act as the high-performance electrocatalytic electrode: the interconnected porous $\mathrm{CoMoO}_{4}$ nanocrystals with sufficient defects can provide sufficient active sites for electrochemical conversion reaction, while the $3 \mathrm{D}$ conductive struts and the tightly contact interface can facilitate the electrons transfer rate to ensure the utilization efficiency of the active sites.

The three-electrode system is carried out to investigate the electrocatalytic OER performance of the composites. The LSV curves collected under $5 \mathrm{mV} \mathrm{s}^{-1}$ are shown in Fig. 5a. The
$\mathrm{CoMoO}_{4} / \mathrm{CC}-2$ electrode shows an overpotential of $286 \mathrm{mV}$ at 15 $\mathrm{mA} \mathrm{cm}{ }^{-2}$, which is better than that of the $\mathrm{CoMoO}_{4} / \mathrm{CC}-1$ (307 $\mathrm{mV}), \mathrm{CoMoO}_{4} / \mathrm{CC}-3$ (294 mV), $\mathrm{CoMoO}_{4} / \mathrm{CC}-4$ (398 mV), CC scaffold and commercial $\mathrm{IrO}_{2}(339 \mathrm{mV})$. Moreover, this value is also better than or comparable with that of the state-of-the-art electrocatalysts (Table S3, see ESI $\dagger$ ). Furthermore, the overpotential of the $\mathrm{CoMoO}_{4} / \mathrm{CC}-2$ is still lower than that of the other $\mathrm{CoMoO}_{4} / \mathrm{CC}-n(n=1,3,4)$ electrodes under higher response current density (Fig. 5b). Moreover, The Tafel slopes are calculated to be $71,67,74,73,122$ and $82 \mathrm{mV} \mathrm{dec}^{-1}$ for $\mathrm{CoMoO}_{4} / \mathrm{CC}-1, \mathrm{CoMoO}_{4} / \mathrm{CC}-2, \mathrm{CoMoO}_{4} / \mathrm{CC}-3, \mathrm{CoMoO}_{4} / \mathrm{CC}-4$, $\mathrm{CC}$ and commercial $\mathrm{IrO}_{2}$, respectively (Fig. 5c). The earlier overpotential and smaller Tafel slope of the $\mathrm{CoMoO}_{4} / \mathrm{CC}-2$ composite can be attributed to the improvement of the electrons transfer rate at the contact interface and increased active sites utilization efficiency. ${ }^{28}$ To gain insights into the activity improvement mechanism, the EIS results are presented in Fig. 5d. The $\mathrm{CoMoO}_{4} / \mathrm{CC}-2$ electrode exhibits similar charge transfer resistance with that of the other composites in high 

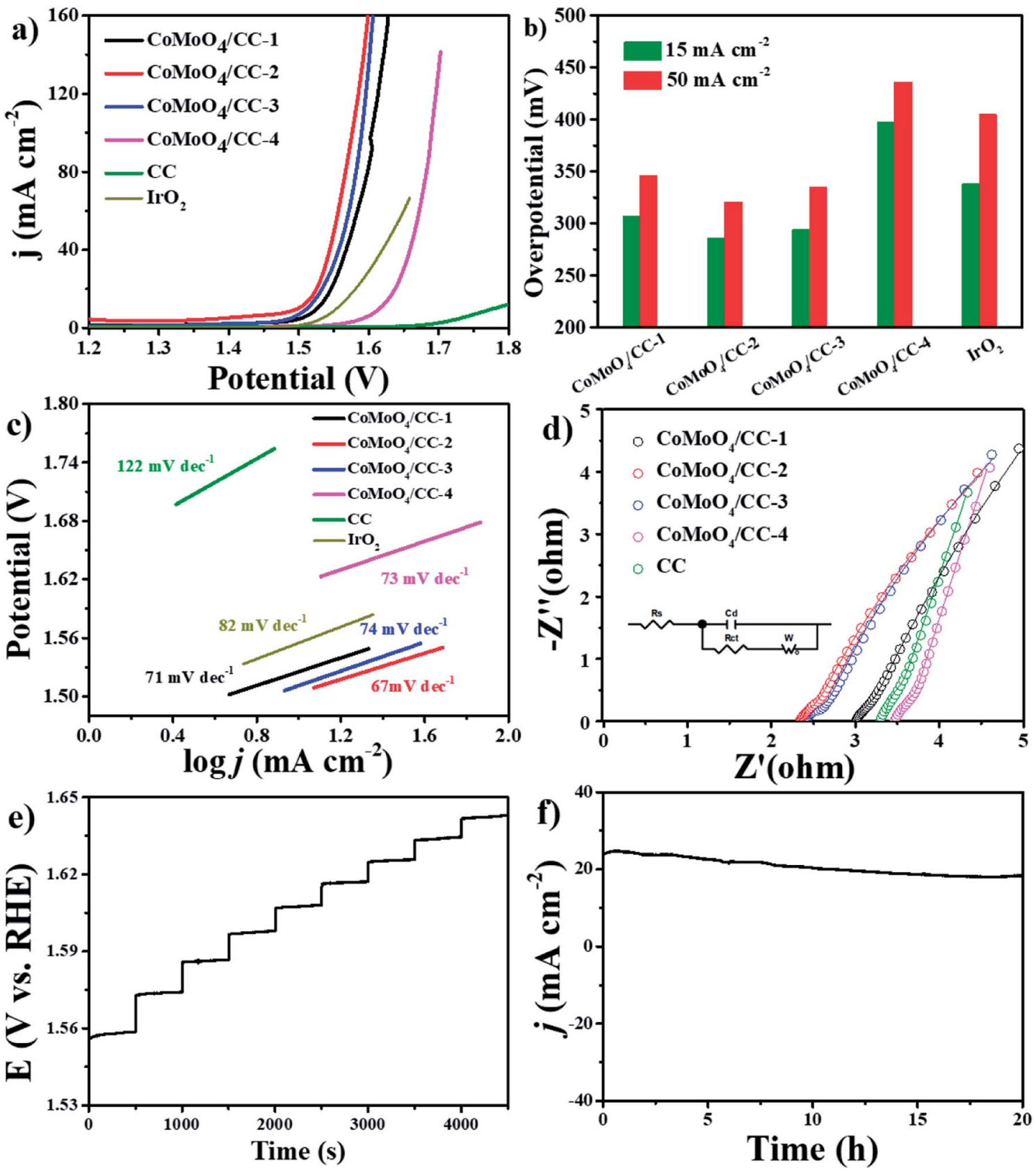

Fig. 5 (a) LSV curves, (b) comparative overpotential (c) Tafel curves (d) EIS curves of the $\mathrm{CoMoO}_{4} / \mathrm{CC}-n(n=1,2,3$ and 4 ) electrodes. (e) Multicurrent process of $\mathrm{COMoO}_{4} / \mathrm{CC}-2$. The current density started at $10 \mathrm{~mA} \mathrm{~cm}{ }^{-2}$ and ended at $50 \mathrm{~mA} \mathrm{~cm}^{-2}$, with an increment of $5 \mathrm{~mA} \mathrm{~cm}{ }^{-2}$ per $500 \mathrm{~s}$ without $i R$ correction. (f) $i-t$ curves of $\mathrm{CoMoO}_{4} / \mathrm{CC}-2$ composite.

frequency region, while the contact interface conductivity is improved clearly with the $R_{\mathrm{S}} 2.2 \Omega$ from the equivalent circuit, which is in accordance with OER catalytic performance. The multi-current responding curve in Fig. 5e reveals the potential stabilized at $1.558 \mathrm{~V}$ under $10 \mathrm{~mA} \mathrm{~cm} \mathrm{~cm}^{-2}$ and similar results remain unchanged at all other steps, illustrating the good conductivity, mass transportation property and mechanical robustness of the 3D $\mathrm{CoMoO}_{4} / \mathrm{CC}-2$ electrode. ${ }^{\mathbf{4 3 , 4 4}}$ Moreover, the long-term stability of the $\mathrm{CoMoO}_{4} / \mathrm{CC}-2$ composites is evaluated by applying a constant potential ( $1.6 \mathrm{~V} v s$. RHE) on the electrode for $20 \mathrm{~h}$ (Fig. 5f). The constant response current density during the period indicates good electrocatalytic stability of the $\mathrm{CoMoO}_{4} / \mathrm{CC}-2$ composites. ${ }^{45}$ Furthermore, the SEM, XRD, XPS and TEM results of the $\mathrm{CoMoO}_{4} / \mathrm{CC}-2$ electrode after the longterm catalytic test also reveal the superior structural and crystalline stability of the nanosheets (Fig. 6 and S4-S6, see ESI†).

To estimate the ECSA of the electrodes and understand the relationship between the active material crystal structure and OER activity, the CV tests are conducted in the region of 1.276 to $1.376 \mathrm{~V} v$ s. RHE under different scan rates (Fig. 7a and $\mathrm{S} 7 \dagger$ ). As the response current density should only be relevant to the electrical double layer surface area $\left(C_{\mathrm{dl}}\right)$, thus the ECSA of the 

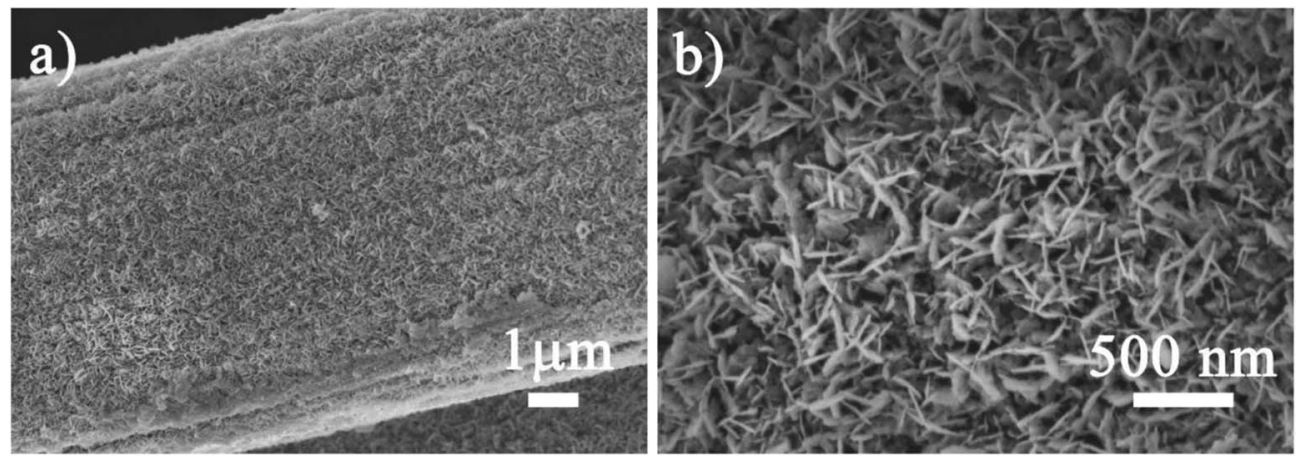

Fig. 6 (a) The low-magnification and (b) low-magnification SEM images of the $\mathrm{CoMoO}_{4} / \mathrm{CC}$-2 electrode after long-term catalytic stability test.
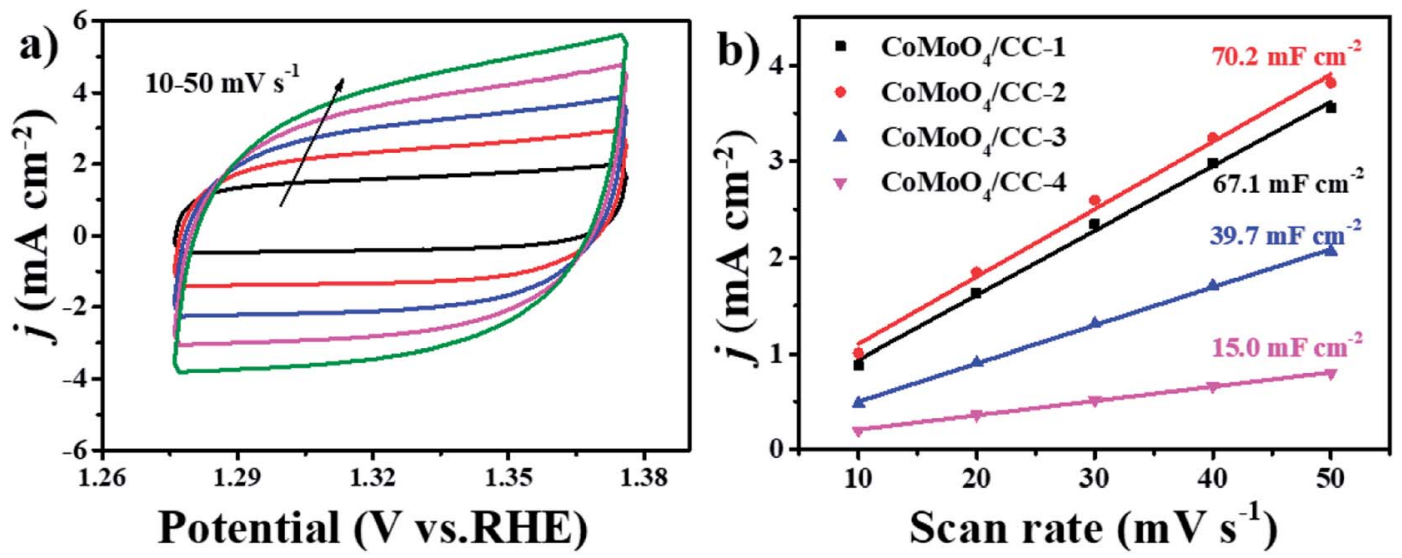

Fig. 7 (a) $\mathrm{CV}$ curves of the $\mathrm{CoMoO}_{4} / \mathrm{CC}-2$ at different scan rates from 10 to $50 \mathrm{mV} \mathrm{s}^{-1}$, (b) estimated $C_{\text {dl }}$ and relative electrochemically active surface area of the $\mathrm{CoMoO}_{4} / \mathrm{CC}-n$ electrodes.

electrodes can be calculated. ${ }^{46}$ The $\mathrm{CoMoO}_{4} / \mathrm{CC}-2$ sample shows a highest $C_{\mathrm{dl}}$ of $70.2 \mathrm{mF} \mathrm{cm} \mathrm{cm}^{-2}$ (Fig. 7b), which is larger than those of the $\mathrm{CoMoO}_{4} / \mathrm{CC}-1\left(67.1 \mathrm{mF} \mathrm{cm}{ }^{-2}\right), \mathrm{CoMoO}_{4} / \mathrm{CC}-3(39.7$ $\left.\mathrm{mF} \mathrm{cm}{ }^{-2}\right)$ and $\mathrm{CoMoO}_{4} / \mathrm{CC}-4\left(15.0 \mathrm{mF} \mathrm{cm}^{-2}\right)$. The highest $C_{\mathrm{dl}}$ of the $\mathrm{CoMoO}_{4} / \mathrm{CC}-2$ hybrid suggests the enlarged electrocatalytic surface area, thus active sites utilization efficiency of the active material in the catalytic process is also largely increased..$^{47,48}$

\section{Conclusion}

In summary, the three-dimensional (3D) free-standing $\mathrm{CoMoO}_{4}$ nanoarrays with different morphologies anchored on the carbon cloth were synthesized via a one-pot hydrothermal method without post heat treatment. The $\mathrm{CoMoO}_{4}$ morphology evolution with the change of the $\mathrm{Co} / \mathrm{Mo}$ precursor ratio and the materials contact interface is investigated. As the OER electrode, the $\mathrm{CoMoO}_{4} / \mathrm{CC}-2$ composite with interconnected nanosheets reveals superior catalytic activity, the overpotential of $286 \mathrm{mV}$ at $15 \mathrm{~mA} \mathrm{~cm}{ }^{-2}$ and Tafel slope of $67 \mathrm{mV} \mathrm{dec}^{-1}$ can be obtained. Moreover, the $\mathrm{CoMoO}_{4} / \mathrm{CC}-2$ electrode shows high long-term electrochemical and structural stability. As the carbon cloth is commercially available, this simple but effective morphology controlling method can act as a new large-scale practical electrode fabrication technique for large-scale water splitting.

\section{Conflicts of interest}

There are no conflicts to declare.

\section{Acknowledgements}

We appreciate the financially supported by the National Natural Science Foundation of China (21776187, 21490582, 21506130), the State Key Laboratory of Polymer Materials Engineering (Grant No. sklpme2017-3-01) and the Fundamental Research Funds for the Central Universities.

\section{References}

1 M. Armand and J. M. Tarascon, Nature, 2008, 451, 652-657. 2 J. Ji, Y. Li, W. Peng, G. Zhang, F. Zhang and X. Fan, Adv. Mater., 2015, 27, 5264-5279.

3 N.-T. Suen, S.-F. Hung, Q. Quan, N. Zhang, Y.-J. Xu and H. M. Chen, Chem. Soc. Rev., 2017, 46, 337-365.

4 X. Cui, Y. Zhu, F. Li, D. Liu, J. Chen, Y. Zhang, L. L. Zhang and J. Ji, RSC Adv., 2016, 6, 9007-9012.

5 I. Yoshikazu, O. Tatsuhiko, H. Daisuke, W. Mitsuru, N. Yuki, C. Linghan, H. Kailong, I. Masahiko, F. Jun-ichi and A. Tadafumi, ACS Catal., 2018, 8, 3579-3586. 
6 Z. Chen, Y. Song, J. Cai, X. Zheng, D. Han, Y. Wu, Y. Zang, S. Niu, Y. Liu, J. Zhu, X. Liu and G. Wang, Angew. Chem., Int. Ed., 2018, 57, 5076-5080.

7 X. Guo, J. Ji, Q. Jiang, L. Zhang, Z. Ao, X. Fan, S. Wang, Y. Li, F. Zhang, G. Zhang and W. Peng, ACS Appl. Mater. Interfaces, 2017, 9, 30591-30598.

8 F. Wang, Y. Zhu, W. Tian, X. Lv, H. Zhang, Z. Hu, Y. Zhang, J. Ji and W. Jiang, J. Mater. Chem. A, 2018, 6, 10490-10496.

9 Z. Chen, L. Cai, X. Yang, K. Coleman, L. Guo, S. Shen and E. K. Bruce, ACS Catal., 2018, 8, 1238-1247.

10 F. Qin, Z. Zhao, M. K. Alam, Y. Ni, F. C. R. Hernandez, L. Yu, S. Chen, Z. Ren, Z. Wang and J. Bao, ACS Energy Lett., 2018, 3, 546-554.

11 M. Tahir, L. Pan, F. Idrees, X. Zhang, L. Wang, J.-J. Zou and Z. L. Wang, Nano Energy, 2017, 37, 136-157.

12 Y. Lee, J. Suntivich, K. J. May, E. E. Perry and S. H. Yang, J. Phys. Chem. Lett., 2012, 3, 399-404.

13 C. C. L. McCrory, S. Jung, J. C. Peters and T. F. Jaramillo, J. Am. Chem. Soc., 2013, 135, 16977-16987.

14 X. Lv, Y. Zhu, T. Yang, H. Zhang, X. Cui, H. Yue, D. Liu, J. Chen and J. Ji, Ceram. Int., 2016, 42, 19006-19011.

15 H. Zhang, X. Lv, F. Wang, H. Zhufen, H. Han, X. Fan and J. Ji, Ceram. Int., 2018, 44, 7611-7617.

16 Y. Wang, T. Zhou, K. Jiang, P. Da, Z. Peng, J. Tang, B. Kong, W. Cai, Z. Yang and G. Zheng, Adv. Energy Mater., 2014, 4, 1400696.

17 X. Liu, W. Xi, C. Li, X. Li, J. Shi, Y. Shen, J. He, L. Zhang, L. Xie, X. Sun, P. Wang, J. Luo, L. Liu and Y. Ding, Nano Energy, 2018, 44, 371-377.

18 J. Zhao, X. Ren, H. Ma, X. Sun, Y. Zhang, T. Yan, Q. Wei and D. Wu, ACS Sustainable Chem. Eng., 2017, 5, 10093-10098.

19 L. Fang, F. Wang, T. Zhai, Y. Qiu, M. Lan, K. Huang and Q. Jing, Electrochim. Acta, 2018, 259, 552-558.

20 Y. Huang, X. Zhao, F. Tang, X. Zheng, W. Cheng, W. Che, F.-C. Hu, Y. Jiang, Q. Liu and S. Wei, J. Mater. Chem. A, 2018, 6, 3202-3210.

21 S. Ye, Z. Shi, J. Feng, Y. Tong and G. Li, Angew. Chem., Int. Ed., 2018, 57, 1-6.

22 J. Qian, Z. Li, X. Guo, Y. Li, W. Peng, G. Zhang, F. Zhang and X. Fan, Ind. Eng. Chem. Res., 2018, 57, 483-489.

23 J. Meng, J.-Q. Fu, X. Yang, M.-J. Wei, S. Liang, H.-Y. Zang, H.-Q. Tan, Y.-H. Wang and Y.-G. Li, Inorg. Chem. Front., 2017, 4, 1791-1797.

24 J. Ji, J. Liu, L. Lai, X. Zhao, Y. Zhen, J. Lin, Y. Zhu, H. Ji, L. L. Zhang and R. S. Ruoff, ACS Nano, 2015, 9, 8609-8616.

25 K. Chi, Z. Zhang, Q. Lv, C. Xie, J. Xiao, F. Xiao and S. Wang, ACS Appl. Mater. Interfaces, 2017, 9, 6044-6053.

26 Y. Li, H. Xu, H. Huang, C. Wang, L. Gao and T. Ma, Chem. Commun., 2018, 54, 2739-2742.
27 F. Wang, X. Lv, L. Zhang, H. Zhang, Y. Zhu, Z. Hu, Y. Zhang, J. Ji and W. Jiang, J. Power Sources, 2018, 393, 169-176.

28 K. Yan, J. Qin, Z. Liu, B. Dong, J. Chi, W. Gao, J. Lin, Y. Chai and C. Liu, Chem. Eng. J., 2018, 334, 922-931.

29 Y. Zhu, F. Wang, H. Zhang, X. Lv, Z. Hu, H. Han, X. Fan, J. Ji and X. Guo, J. Alloys Compd., 2018, 747, 276-282.

30 Z. Tong, D. Yang, X. Zhao, J. Shi, F. Ding, X. Zou and Z. Jiang, Chem. Eng. J., 2018, 337, 312-321.

31 H. Huang, C. Yu, X. Han, S. Li, S. Cui, C. Zhao, H. Huang and J. Qiu, Ind. Eng. Chem. Res., 2017, 56, 14245-14251.

32 L. Wang, H. Yang, X. Liu, R. Zeng, M. Li, Y. Huang and X. Hu, Angew. Chem., Int. Ed. Engl., 2017, 56, 1105-1110.

33 L. Mai, F. Yang, Y. Zhao, X. Xu, L. Xu and Y. Luo, Nat. Commun., 2011, 2, 381-386.

34 G. K. Veerasubramani, K. Krishnamoorthy and S. J. Kim, J. Power Sources, 2016, 306, 378-386.

35 A. P. d. Moura, L. H. d. Oliveira, P. F. S. Pereira, I. L. V. Rosa, M. S. Li, E. Longo and J. A. Varela, Adv. Chem. Eng. Sci., 2012, 02, 465-473.

36 P. Wu, S. Cheng, M. Yao, L. Yang, Y. Zhu, P. Liu, O. Xing, J. Zhou, M. Wang, H. Luo and M. Liu, Adv. Funct. Mater., 2017, 27, 1702160.

37 Z. Lv, M. Tahir, X. Lang, G. Yuan, L. Pan, X. Zhang and J. Zou, J. Mater. Chem. A, 2017, 5, 20932-20937.

38 B. Ren, D. Li, Q. Jin, H. Cui and C. Wang, J. Mater. Chem. A, 2017, 5, 24453-24461.

39 R. Wei, M. Fang, G. Dong, C. Lan, L. Shu, H. Zhang, X. Bu and J. C. Ho, ACS Appl. Mater. Interfaces, 2018, 10, 7079-7086.

40 X. Lv, H. Zhang, F. Wang, Z. Hu, Y. Zhang, L. Zhang, R. Xie and J. Ji, CrystEngComm, 2018, 20, 1690-1697.

41 Z. Liu, Z. Zhao, Y. Wang, S. Dou, D. Yan, D. Liu, Z. Xia and S. Wang, Adv. Mater., 2017, 29, 1606207.

42 Y. Wang, T. Li, Z. Xiao, R. Chen, Z. Jiang and S. Wang, Adv. Funct. Mater., 2018, 28, 1705356.

43 M. Xie, L. Yang, Y. Ji, Z. Wang, X. Ren, Z. Liu, A. M. Asiri, X. Xiong and X. Sun, Nanoscale, 2017, 9, 16612-16615.

44 Y. Wei, X. Ren, H. Ma, X. Sun, Y. Zhang, X. Kuang, T. Yan, H. Ju, D. Wu and Q. Wei, Chem. Commun., 2018, 54, 15331536.

45 X. Ren, R. Ge, Y. Zhang, D. Liu, D. Wu, X. Sun, B. Du and Q. Wei, J. Mater. Chem. A, 2017, 5, 7291-7294.

46 S. Trasatti and O. A. Petrii, J. Electroanal. Chem., 1992, 327, 353-376.

47 D. Wu, Y. Wei, X. Ren, X. Ji, Y. Liu, X. Guo, Z. Liu, A. M. Asiri, Q. Wei and X. Sun, Adv. Mater., 2018, 30, 1705366.

48 X. Ren, X. Ji, Y. Wei, D. Wu, Y. Zhang, M. Ma, Z. Liu, A. M. Asiri, Q. Wei and X. Sun, Chem. Commun., 2018, 54, 1425-1428. 